\title{
Living environment originality in the historical center of the settlement on the Kuban example
}

\author{
Oleg Subbotin* \\ Kuban State Agrarian University named after I.T. Trubilin, 350044, Krasnodar, Russia
}

\begin{abstract}
The historical center of the settlement, its unique buildings, natural landscape, as well as the objects of architectural heritage from the point of view of national culture are considered. In the process of system analysis, the urban identity of the historical center was revealed from the standpoint of the living environment quality. It is indicated that one of the main tasks in the strategic planning of the historical center is the organization of its attractive space, in the context of creating a high level of living environment, the activity of cultural pastime. Particular attention is focused on the need to preserve the historical center, which is an important planning link in the urban planning structure of the settlement.
\end{abstract}

\section{Introduction}

Preserving and increasing the cultural potential of the historical center of urban and rural settlements is a relevant topic throughout the long stages of their development, which are clearly reflected in the monuments of architectural heritage that form the appropriate living environment.

Currently, this topic is rightfully elevated to the rank of national urban planning policy and is properly taken into account when drawing up plans for strategic territorial planning. The fate of historical centers is multifaceted, complex, and at the same time often pensive. To a large extent, this depended on a number of circumstances, as a result of which the authentic buildings were preserved, at best, in a fragmentary form, within the boundaries of the localized core of the historical center, practically in their original state. At the same time, the loss of significant background historical buildings is also noted. At the same time, in the center of a number of settlements, certain elements of the historical past have been preserved - iconic monuments of the architectural heritage - valuable city-forming objects, temples, which are the main high-rise dominants.

At the same time, "the aspiration of architectural forms upward, as a feature specific to the Russian building tradition, was clearly revealed in the appearance of a number of monuments" [1]. In their unity, these compositional accents, in combination with the natural environment, formed the planning framework of the historical center. "The architects took into account the general nature of the surrounding nature, with which they perfectly knew how to combine their structures [2,3].

\footnotetext{
* Corresponding author: subbos@yandex.ru
} 


\section{Purpose, objectives, research methods}

The aim of the study is a systematic approach to the analysis of the settlement's historical center current state, in the context of its historical and town planning value for the favorable living environment formation.

In accordance with the set goal, the following research tasks are determined:

- to identify the principles of the settlement's historical center planning organization based on a retrospective analysis;

- to determine the factors influencing the living environment quality in the historical center of the settlement;

- to propose measures to preserve the unique cultural potential of this center;

The object of the research is the regularities of the settlement's historical center formation and development, from the point of view of the living environment organization.

The subject of research is the historical architectural and planning structure of the settlement center.

Research methods include:

- compositional and aesthetic analysis of the settlement's historical center planning techniques;

- typological analysis of monuments of architectural heritage and city-forming objects;

- system analysis of the settlement center in historical and cultural unity, as an integral mechanism of its space genesis for the formation of a comfortable environment for life.

The practical value of the research results - the results can be used in the development of projects for the historical boundaries of the settlements' territories, as well as urban planning regulations.

Considering the relevance of the stated topic, it should be noted that within the boundaries of six settlements of the Krasnodar Territory - Anapa, Armavir, Yeysk, Krasnodar, Sochi and the village of Taman, the center has the legislative status of a historical settlement of regional significance (Fig. 1).

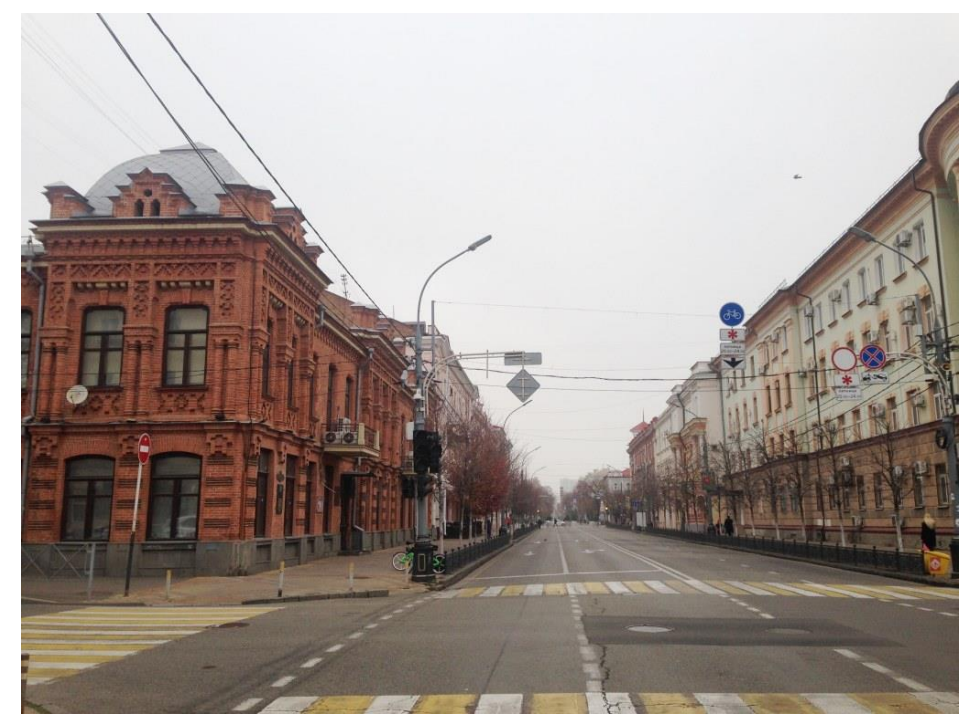

Fig. 1. The historical center of Krasnodar. North side Krasnaya Street at the intersection with Komsomolskaya Street (Headquarters). On the left is the house of General I.K. Nazarov (built in 1889). Modern look 
Historical settlements have a unique cultural and historical potential, which includes not only the features of traditions, customs, way of life of different peoples in the form of a combination of cultural and social heritage [4], but also the objects of architectural heritage. Each such settlement, rich in amazing history, is unique and peculiar in its own way, helps to attract attention to it not only of its citizens, but also of numerous tourists who want to "touch" its history and culture.

\section{Retrospective analysis of the historical center identity in the settlement system}

For the most part, the uniqueness of the author's idea of an architect was personified in his unique architectural object, reflected in the external appearance of the complex, building or structure, being an adornment of the living environment in the historical center of the settlement.

A favorable atmosphere, comprehensive landscaping and natural landscape have a truly magical effect on the visual perception not only of the architectural heritage monument itself, but also on the surrounding reality. A significant part of the objects in the historical center have similar methods of planning, composition and facade solutions. The buildings later on completion are a kind of predecessors of the previously built objects, which at the same time do not violate the volumetric-spatial composition of the historical territory. The interconnected components of the natural territorial complex make a significant contribution to the exceptional identity of the urban landscape.

In landscape unity, both monuments of different significance (federal, regional, local) and buildings that do not have the status of monuments and newly identified objects, but are certainly an integral element of a single cultural (man-made) landscape, inextricably coexist [5].

Mainly, the historical center of the city demonstrates the harmonious unity of the volumetric-spatial composition, the rarest examples of the architecture and the architectural styles of the past [6].

In general, all this creates an excellent opportunity to create perfect conditions in terms of the spatial organization of the historical center, while improving its rich image and improving the living environment.

Most of the previously formed historical centers, in which a regular orthogonal layout can be traced, a clear organization of space, with appropriate landscaping and landscaping, and most importantly, a formed system of view perspectives, have almost completely entered the structure of modern master plans for settlements.

It is known that the city plan changes more slowly than its building. With a multiply updated volumetric structure, the planning scheme continues to be the most ancient and therefore the most valuable part of the urban organism from a historical point of view [7, 8].

At the same time, in the historical settlements of the Krasnodar Territory, the territorial identity of the settlements' central part, the initial planning of which was dictated by strategic functions, namely the construction of fortifications, is traced. The excellent location chosen for them, as the forward strongholds, served as a reliable defense of the southern borders of the Russian Empire. Accordingly, the existing character of the Kuban settlements in the late 18th - early 19th centuries, combining military service with agricultural labor, was directly reflected in the formation of the living environment. At the same time, it is necessary to take into account the objective circumstance that only in 1868 a resolution of the State Council was issued "On allowing Russian subjects of the nonmilitary estate to settle and acquire property in the lands of the Cossack troops." 
The Cossacks built up settlements with wide and fairly straight streets in the center of the settlement with Cathedral Square and a church in the middle. The bazaar (trading) square existed separately or could also be one with the Cathedral. But at the same time, if a strict planning structure was noted in the Black Sea coastal villages, then in the linear villages there was mainly a free picturesque layout, due to the natural conditions of the area. During the formation of the central part of the settlements, the corners of the Cossack quarters were trying to be "fixed" with stone buildings (Fig. 2).

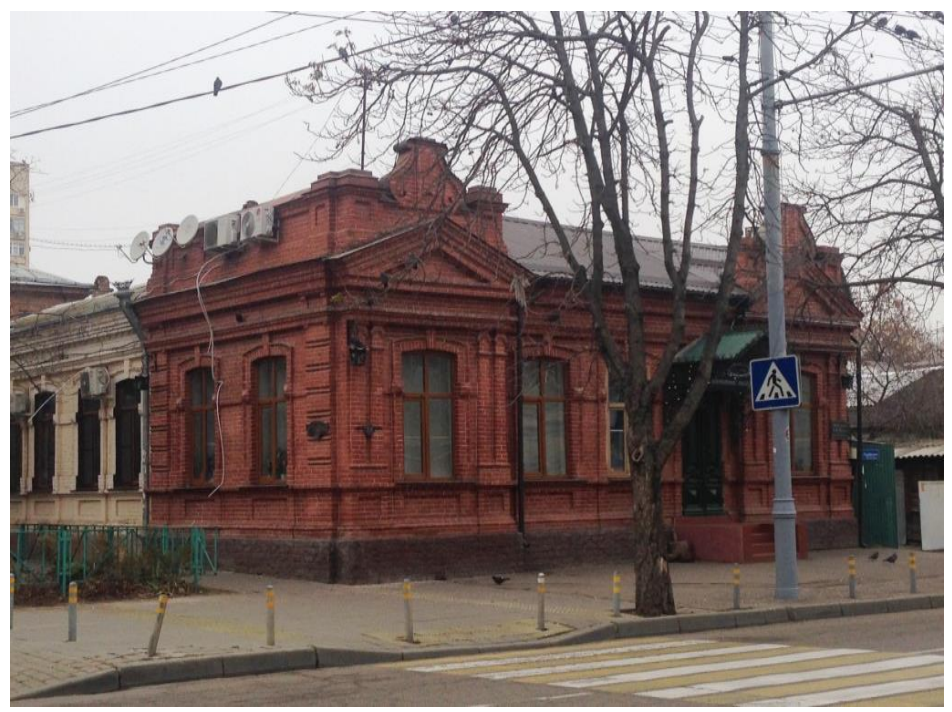

Fig. 2. Fragment of buildings in the historical quarter of Krasnodar. Pushkin Street (Krepostnaya), 25 and Octyabrskaya (Pospolitakinskaya), 33. In the foreground is the residential house of A.I. Orlov, late XIX - early XX century. Modern look

In the historical part of the settlement "in a number of cases, these buildings and structures belong to outstanding examples of a certain historical era in which they were built and, along with the monuments of architectural and urban planning heritage, play an important role in the preserved urban spatial environment, in the ensembles of a historical urban or rural settlement [9].

It should be especially noted that new incarnations of ideas in the architecture of the historical centers of the Kuban are observed at the turn of the late 19th - early 20th centuries. "The beginning of the new century turned out to be the most intensive in terms of construction $[10$, p. 13].

\section{The main factors and priority areas affecting the preservation and restoration of the historical center}

At the same time, many different factors directly affect the organization of a high-quality living environment in the historical center, among which the ecological aspect plays an important role. This aspect is a kind of basic basis for the strategic planning of the historical territory, in the context of the biological diversity creation, namely, green public spaces, while preserving the natural features of the landscape for the formation of a high level of the specified environment. Particular attention should be paid to the intracity transport infrastructure, its accumulation in the historical part, which significantly affects the environmental situation in historical buildings and areas of dilapidated residential buildings, in some cases with a lack of comfortable living conditions. Along with this the ecological 
situation in the existing functional and planning structure of the historical center is also determined by a diverse approach to the natural frame organization.

The safety of the ecological situation by means of competent planning, proper improvement contributes to the improvement of the quality of the living environment both in the interests of the residents of the historical center and the increase in tourist interest in it, which directly affects the development of the settlement's economy and the tourism industry. All this requires a significant investment, while it is necessary to develop an extensive environmental program for the historical center development.

Ecological balance violation in the historical center will inevitably lead to a decrease in the level of the living environment comfort, therefore, a rational combination of natural and artificial components of an urban or rural settlement is necessary. For example, a harmonious combination of water bodies, natural relief with the road network, buildings and structures. "The level of full-fledged engineering support and analysis of factors affecting the comfort and environmental safety of the living environment are important" [11].

No less importance should be given to the compositional and artistic aspects in the historical center of settlements - historical continuity in the formation of the integrity of new objects and architectural heritage, newly organized public spaces, competent functional zoning and the concept of development, in order to create a favorable living environment. The perception of the harmoniously organized historical and architectural structure of the center, its "green" walking routes, oriented towards the objects of architectural and natural heritage, in many ways contributes to the moral enrichment of people, fostering a respectful attitude of the younger generation to the past.

The value of historical buildings is seen, on the one hand, in its diversity, in compositional merits, on the other, in addressing the culture of the past, in the ability to feel the living presence of this culture, to associate modern culture with it [12].

Priority activities in the historic center should primarily focus on:

- preservation and restoration of the architectural heritage, significant elements of the natural landscape, in particular special natural complexes of historical and aesthetic value, in the context of their unique integrity;

- formation of an integrated and sustainable system of public spaces, including those adapted for people with disabilities and people with limited mobility;

- reconstruction of residential quarters, modernization of housing stock, engineering infrastructure, taking into account the requirements of urban planning regulations within the historic center boundaries;

- preservation and restoration of the volumetric-spatial characteristics of valuable urbanforming objects in combination with historically valuable traditional buildings;

- allocation of various pedestrian zones in the planning structure of the historical center of the settlement, connecting parks, squares, boulevards, embankments.

- carrying out environmentally oriented activities and subsequent monitoring of the ecological state of architectural objects, allowing to improve the well-being of the living environment.

At the same time, numerous tasks related to the main priority architectural activities carried out in the historical center of the settlement "relate to both compositional and deeper issues related to the artistic and imaginative side of urban ensembles" [13].

\section{Conclusion}

Thus, when organizing the space, as well as the space-planning structure state, the architectural appearance in the historical center of the settlement, it is necessary, first of all, to identify its most stable characteristics, which make it possible to create a high level of 
comfort of the living environment. An important condition for the formation of this level of comfort is the preservation in modern architectural practice of specific urban planning traditions in the formation of public spaces in historical territories.

When designing the historical center of the settlement, it is necessary to observe the proportionality of ordinary architectural objects to the human scale, orderliness and originality of planning decisions. Despite the new dynamic processes in the socio-economic development of settlements, the high requirements for their historical territory make it possible to create a certain favorable living environment in this territory.

A responsible role in this respect is assigned to an architect who is capable of fully implementing programs for the preservation and restoration of the architectural and urban planning heritage in the historical center of the settlement, the integrity of the cultural potential, contributing to the moral and aesthetic education of society.

Professionally executed architectural and urban planning solutions in the historical center allow preserving its amazing and original appearance, which is one of the design basic principles in this center [14]. It is necessary to have a clear understanding of the volumetric-spatial structure of the historical center, the continuity of its architectural objects and territorial-planning structure in conjunction with the surrounding natural landscape.

\section{References}

1. V.G. Lisovsky, Russian architecture of the 18th - early 20th centuries. The search for a national style (WHITE CITY, Moscow, 2009)

2. N.I. Brunov, Masters of Old Russian architecture (State edition on building and architecture, Moscow, 1953)

3. A.A. Aloyan, A.Yu. Safaryan, Peculiarities of Urban Strategy Formation of the Republic of Armenia Advanced Materials Research (Switzerland, Trans Tech Publications) 1020, 875-878 (2014)

4. O.S. Subbotin, IOP Conference Series: Materials Science and Engineering 913 (3), $032021(2020)$

5. S.V. Sementsov, Bulletin of St. Petersburg State University. Series 2, 190-211 (2013)

6. O.S. Subbotin, Materials Science Forum 931, 745-749 (2018)

7. Monuments of Russian architecture and monumental architecture. Style, attribution, dates (Publishing house. "Nauka", Moscow, 1983)

8. A.Yu. Safaryan, Yu.A. Safaryan, IOP Conf. Ser.: Mater. Sci. Eng. 913, 032015 (2020)

9. O.S. Subbotin, IOP Conference Series: Materials Science and Engineering 698 (3), 033045 (2019)

10. S.P. Zavarikhin, City and architect. Architectural School of Civil Engineers in St. Petersburg (SPbSACU, SPb, 2007)

11. O.S. Subbotin, IOP Conference Series: Materials Science and Engineering 698 (3), 033044 (2019)

12. A.S. Schenkov, Reconstruction of historical buildings in Europe in the second half of the XX century: Historical and cultural problems (LENAND, Moscow, 2011)

13. T.F. Savarenskaya, West European urban planning of the 17th - 19th centuries. (Stroyizdat, Moscow, 1987)

14. O.S. Subbotin, IOP Conference Series: Materials Science and Engineering 913 (3), 032020 (2020) 